\title{
The needs of family members of critically ill patients: a literature review
}

Maria Mei Yuk Chan RN; BN, MSc (Nursing), Staff Nurse, Queen Elizabeth Hospital, Hong Kong

Sek Ying Chair RN; MBA, PhD, Assistant Professor, The Nethersole School of Nursing, The Chinese University of Hong Kong, Hong Kong

E-mail: sychair@cuhk.edu.hk

Key Words: communication family needs information social resources

\section{SUMMARY}

- Recognition of family needs is important and should be incorporated into patient care especially within intensive care settings.

- Family needs include information needs, social needs, emotional needs and practical needs.

- Flexible visiting hours, adequate knowledge and effective communication skills will facilitate nurses' to assess family needs accurately.

\section{INTRODUCTION}

The critically ill patient, due to complexity of their multi-system disease, requires intensive attention and care from healthcare members. Working in the intensive care unit (ICU) can be stressful as nurses are dealing with life and death situations. However, having a family member admitted into ICU is even more stressful for the whole family. Stress may forbid family members' coping mechanisms and thus may affect their ability to provide support to the patients. The recognition of a family's difficult experience is important and should be incorporated into nursing care because families are an extension of the patient and therefore they should be included in the process of care along with the patients.

\section{LITERATURE REVIEW}

Hospitalisation in ICU following a critical or serious illness is viewed as a crisis for both patients and families (Lee \& Lau, 2003; Fok et al., 2005). While providing holistic care, acute life threatening illnesses represent a crisis situation not only for individual patients but also for family members. Patients experience physiologic crisis and family members may be in a state of psychological crisis at the same time (Browning \& Warren, 2006). Hospitalisation in an ICU often occurs without any warning, leaving little time for families to prepare. It is a catastrophic event for families, creating emotional upsets, anxiety, uncertainty, and fear of losing a loved one. Stress also makes family members feel disorganised and helpless (Van Horn \& Tesh, 2000). The literature reports that family members experience high level of stress when patients are admitted to ICU (Holden et al., 2002; Ucar \& Selimen, 2005). Family members may also close themselves off from the outside world (Mendonca \& Warren 1998; Neabel et al., 2000). As a result, they often show difficulty in mobilising appropriate coping resources (Soderstrom et al., 2006). This will then compromise their ability to interact and support the patients, and hence affect patients' treatment response (Pochard et al., 2001).

ICU nurses are in continuous and close interaction with patients and family members; they are in an ideal position to help family members to cope with patients' critical illness in an adaptive way (Lee \& Lau, 2003). Responding to family members' needs during the early crisis period is significant because this can lesson the negative impact of stress (Holden et al., 2002; Ucar \& Selimen, 2005; Browning \& Warren, 2006). If the needs of family members can be easily understood and facilitated, both family and patient caring can be achieved in a desirable consequence. In fact, their needs can be categorised as following: information needs, social needs, emotional needs and practical needs (Verhaeghe et. al., 2005).

\section{Information}

Good communication between health care staff and families is essential. In fact, most families rate the importance of clinicians' communication skills above their clinical acumen (Curtis et al., 2001). Information appears to be the greatest need of family members of critically ill patients worldwide. In Hong Kong, people have recently become more aware of their right of access to information related to their relatives' condition and treatment (Lee \& Lau, 2003). Lam and Beaulieu (2004) describe information-seeking behaviour as a way families cope with their stress and anxiety. The unknown is frightening and information serves as an antidote.

Two recent studies found that information was the top priority for families in Hong Kong (Lee et al., 2003; Chien et al., 2006). American families also concur and ask for accurate and consistent information at the beginning and throughout their ICU experience (Bond et al., 2003). In the study by Bond et al. family members stated that the doctor and then the nurse should be initiating the provision of information. More specifically, family members want accurate and specific information from the doctor about the condition, the prognosis and the precise treatment of the patient at least once a day. For nurses, families expect information about daily care of the patient, the reasons of particular treatments, the equipment and the various disciplines present in the unit, and what families can do at the bedside for the patient. Moreover, family members are expected to be called at home about any changes in the condition of the patient and speak to the same nurse as much as possible (Bond et al., 2003). However, being able to talk to the same nurse every day may be problematic in that nurses have days off and may be assigned to other patients to accommodate the work flow of the 
unit. Browning and Warren (2006) suggested that a good response to these changes might be for the nurse to introduce the new nurse who would be taking care of that patient.

High-quality communication begins with the very first encounter between the family and the ICU team. Trust between nurses and families must be quickly established. Complex and sophisticated illness and technology must be explained in straightforward, simple understandable language (Lorin et al., 2006). Effective communication is a skill that requires training and practice in the same manner as any technical skill would. For example, setting a non-threatening tone, tolerating silence, identifying and acknowledging family's feelings, and acknowledging the difficulty of the situation and decisions are important skills during delivering information to the families (Boyle et al., 2005). The provision of information concerning the patient's disease, treatment, progress, and outcome is an important need for families.

\section{Emotional support}

In some cases, the need for hope and reassurance seems even greater than the need for information. Lee and Lau (2003) investigated the immediate needs of family members of adult ICU patients in Hong Kong. The reassurance category was identified, as the most important need category. Hope appears to be of greater important in sudden, unexpected and serious changes in the condition of critical illness, which often occurs without warning and gives little time for patients and their families to prepare. For example, a comatose patient due to trauma is clearly a sudden, unexpected and serious change in the state of health of a person, so it is reasonable to assume that the need for hope is practically great in this case.

Chien et al. (2005) found that instilling realistic hope in recovery for a relative with critical illness or psychological preparation for facing a relative's death is considered to be an important psychological support for Chinese families to cope with the crisis. As for the need for reassurance, family members state that they certainly want to be called at home if the condition of the patient changes and that they want to be sure that the patient is receiving best possible care and is as comfortable as possible (Verhaeghe et. al., 2005). Psychological assurance from health professionals that the best care is being provided for the patient has been shown to induce a sense of security and a feeling of being cared for (Hallgrimsdottir, 2000).

Family members of trauma patients and neurological patients consider the need for spiritual support and the presence of a priest in the vicinity more important than do family members of the other groups (Lam \& Beaulieu, 2004). In some studies, comparing scores on needs given by nurses and family members shows that nurses generally underestimate the emotional needs of family members, and doctors also seem to be insufficiently concerned about the emotional needs of family members (Holden et al., 2002).

\section{Social support}

Regarding social needs, all the needs that concern relationships between people should be considered by nurses. This can be the relationship between the patient and his family members as well as the relationship between family members and friends. In some studies, social needs are generally considered less important than other needs (Lee \& Lau, 2003).

Throughout one's life, physical contact and maintaining healthy relationships with others are important. Mothers and infants establish the intimate bond with repeated physical and emotional contact. When one member of a relationship is stressed, this learned behavior instills the need for people to want to be close to one another (Feldman \& Eidelman, 2006). The need for proximity such as the facility for family members to stay with the ill person 24-hourly at the bedside has been reported as the most important need perceived by families during patients' hospitalisation (Chien \& Lee, 2005). Chien and Lee found that Chinese families show their concerns and feelings for each other by taking care of each other's actual needs rather than by communicating those feelings in words, as preferred by Western people. Besides, families of critically ill patients express the need for closeness to their loved ones, and why it helps them to cope with their stressful situation. Proximity is very important to someone whose spouse is in ICU (De Jong \& Beatty, 2000). Being physically and emotionally present at the bedside is important so that they can respond to perceived needs of their spouses. A Swedish study (Engstrom et al., 2004) also focused on the needs of spouses and found similar results.

Depression and anxiety are common in families of critically ill patients (Foster \& Chaboyer, 2003; Jones et al., 2004). Despite expressing feelings of fear and anxiety in seeing their relative in a critically ill state, presence at the bedside is cited as the single most important need for spouses. Families feel the need to re-establish a connection, regardless of the level of consciousness of their loved one or their ability to comprehend or respond (Holden et al., 2002). Families want their loved ones to know they are not alone and being physically present at the bedside is an important initial step in the process.

\section{Comfort support}

Practical needs generally concern the family member's feeling of comfort, in which both material and non-material needs, with flexible visiting hours, with help of financial or family problems and explanation of what family can do at the bedside of patient and how they can contribute to the care of patients (Verhaeghe, et. al., 2005). An environment with sofas and recliners, television, reading materials may be provided within the waiting room so that families may feel more comfortable. These gestures are usually accepted by the hospital staff (Browning \& Warren, 2006).

Traditionally, hospital and critical care units implement restrictive visiting hours for patients' families and friends to reduce the interference with patient care, and physical and emotional stress for the patient, to maintain confidentiality, and due to concerns about infection control (Berwick, 2004). Furthermore, the culture of the unit, personal attitude and unforeseen disasters may all negatively influence a visiting policy (Livesay et al., 2005; Takman et al., 2005).

A study by Marco et al. (2006) found that although there was more environmental contamination with unrestricted visiting policy, there was no increase in infectious complications in patients. Flexible visitation policies maximise access between family members and their dying loved one (Kjerulf, et al., 2005). Marco et al. (2006) suggested that families provide emotional support to the patient, increase their desire to live and is not destabilising. At the same time, family members also feel more satisfied and less anxious as they receive more updated information about the patient's condition. It can create an atmosphere which is beneficial to the convalescence of the patient. However, this may depend as much on the characteristics of the patient as on those of the family (Marco et al., 2006).

Strategies to improve quality of care to patients and family members

Critical care nurses are expected to provide care to critically ill patients. In Hong Kong, critical care nurses are well educated and trained; and many of them are certified to facilitate the stabilisation and recovery of critically ill patients. Algorithms, protocols, procedures, advanced training, continuing education, and effective communication with other members of the healthcare team help guide the critical care nurse to optimise the health of critically ill patients. However, many expert critical care nurses feel ill-equipped to meet the needs of family members (Holden et al., 2002). Critical care nurses are proud of providing expert care, but often they feel frustrated with inadequate 
knowledge and support in meeting the needs of both patients and family members in aspects other than physiologically.

\section{Empathy, experience and assessment}

Some studies have investigated the degree of empathy and the length of experience of nurses and their affect on family needs assessment (O'Malley et al. 1991, Murphy et al. 1992). Nurses who scored better on empathy had a better insight into only a few needs of family members than those who were classified as being less empathetic. Empathetic nurses could only better assess family needs related to access to the unit (O'Malley et al. 1991, Murphy et al. 1992). Although nurses were empathetic, they had little chance to speak to the family due to the restriction in visiting hours. The amount of experience correlated negatively to the ability of the assessment in family needs. Nurses who were more experienced had less ability to assess family needs (O'Malley et al. 1991). It was possible that training rather than experience influenced the assessment as well as the provision of better care to meet family needs and nurses with less experience might be better prepared in this aspect in their education (O’Malley et al. 1991).

\section{Improved communication}

Patients and families often depend on nurses for knowledge and guidance. At the time of admitting a patient, the family and clinician may have a conversation about treatment preference. Communication should focus on realistic and achievable goals rather than consent for specific treatment. Curtis and Patrick (2001) stated that to affect communication requires training, practice, planning and preparation. Good communication skills include listening attentively, addressing concerns, dealing empathetically with emotions, and frequent contact (Curtis \& Patrick, 2001).

\section{Utilise support and resources to improve care}

Other than providing care, nurses should assist families in mobilising resources and coping to decrease stress. Nurses can help, for example, by identifying their supporting systems and making referrals to community resources such as social welfare or services that may be needed after discharge. Supporting families to ensure that they access services is critical to help them cope with the care of a loved one (Dobrof et al., 2006).

Families of critically ill patients have an increased need for information. A multidisciplinary team approach may synergise the effect of helping families to meet their needs. The multidisciplinary team should include physicians, advanced practice nurses, social workers, physical therapists, dietitians, speech therapists, occupational therapists and pastoral care. All members of the team can provide specific information to the particular needs of patients and families. Team communication and nurse-physician collaboration can be enhanced by participation in ward rounds, as this is often the best time to discuss the goals of care and patients' and families' needs and values with colleagues.

\section{Information resources}

Written information, such as leaflets and booklets, has been used to enhance communication between patients, families and health care professionals (Leung et al., 2000). Many ICUs provide information for patients and relatives about the environment and various treatments. However, limited information is prepared for patients who will be transferred to a general ward after ICU (Mitchell \& Courtney, 2005). Families may have a sense of sudden abandonment, pervasive feelings of vulnerability and helplessness, a loss of importance and ambivalence about the experience (Chaboyer et al., 2005). Mitchell and Courtney (2005) suggested that face-to-face communication and an individualised brochure for the family contributed significantly to families' satisfaction, preparation and communication about patient transfer. The need for improved continuity of care after ICU and the need to increase patient and relative awareness of recovery process after critical illness should also be highlighted. The booklet can assists patients and relative throughout the recovery period by empowerment and also provide advice on how to deal with common problems.

\section{CONCLUSIONS}

Although there are many needs that nurses may not able to provide to family members, reassurance is the best possible care and should be given priority. The physical and emotional presence of nursing staff is important to family members. To meet relatives' needs flexible visiting hours can be introduced or the family member should be enabled to stay with the patient for as long as they wish. In addition, a practice of giving daily reports to families by the primary nurses in person or by telephone should be considered. Thus family members could receive information regarding the patient's disease, progress and medical treatment every day, including when they are not able to visit.

Due to the crisis of the illness, family members' ability to receive and process information may be impaired. Therefore information should be provided in simple and non-technical terms. Finally, in order to be able to identify needs accurately, an adequate knowledge base and communication skills in assessing and meeting family needs should be incorporated in nursing education as well as topics for continue education.

\section{REFERENCES}

Berwick DW, Kotagal M (2004). Restricted visiting hours in ICUS waiting rooms. JAMA 29(2), 736-737.

Bond AE, Draeger CR, Mandleco B, Donnelly M (2003). Needs of family members of patients with severe traumatic brain injury. Implications for evidence-based practice. Critical Care Nursing 23(2), 63-72.

Boyle DK, Miller PA, Forbes-Thompson SA (2005). Communication and end-of-life care in the intensive care unit: patient, family, and clinician outcomes. Critical Care Nursing Quarterly 28(4), 302316.

Browning G, Warren NA (2006). Unmet needs of family members in the medical intensive care waiting room. Critical Care Nursing Quarterly 29(1), 86-95.

Chaboyer W, Kendall E, Kendall M, Foster M (2005). Transfer out of intensive care: a qualitative exploration of patient and family perceptions. Australian Critical Care 18(4), 138-145.

Chien WT, Chiu YL, Lam LW, Ip WY (2006). Effect of a needsbased education for family carers with a relative in as intensive care unit; quasi-experimental study. International Journal of Nursing Studies 43(1), 39-50.

Chien WT, Ip WY, Lee IYM (2005). Psychometric properties of a Chinese version of the Critical Care Family Needs Inventory. Research in Nursing and Health 28(6), 474-487.

Curtis JR, Patrick DL, Shannon SE (2001). The family conference as a focus to improve communication about end-of-life care in the intensive care unit: opportunities for improvement. Critical Care Medicine 29(suppl. 2), N26-N33.

Curtis JR, Patrick DL (2001). How to discuss death and dying in ICU. New York, Oxford University Press, pp. 85-102.

De Jong MJ, Beatty DS (2000). Family perceptions of support interventions in the intensive care unit. Dimensions of Critical Care Nursing 19(5), 40-47. 
Dobrof J, Ebenstein H, Dodd S, Epstein I (2006). Social work series. Caregivers and professionals partnership caregiver resource center: assessing a hospital support program for family caregivers. Journal of Palliative Medicine 9(1), 196-205.

Engstrom A, Soderberg S (2004). The experience of partner of critical ill persons in intensive care unit. Intensive and Critical Care Nursing 20(1), 229-308.

Feldman R, Eidelman Al (2006). Neonatal state organization, neuromaturation, mother-infant interaction, and cognitive development in small-for-gestational-age premature infants. Pediatrics 118(3), 869-378.

Fok SK, Chair SY, Lopez V (2005). Sense of coherence, coping and quality of life following a critical illness. Journal of Advanced Nursing 49(2), 173-181.

Foster M, Chaboyer W (2003). Family carers of ICU survivors: a survey of the burden they experience. Scandinavian Journal of Caring Science 17(2), 205-214.

Hallgrimsdottir EM (2000). Accident and emergency nurses' perceptions and experiences of caring for families. Journal of Clinical Nursing 9(4), 611-619.

Holden J, Harrison L, Johnson M (2002). Families, nurses and intensive care patients: A review of the literature. Journal of Clinical Nursing 11(2), 140-148.

Jones C, Skirrow P, Griffiths RD (2004). Posttraumatic stress disorder-related of patients following intensive care. Intensive Care Medicine 30(2), 456-460.

Kjerulf M, Regehr C, Popova SR, Baker AJ (2005). Family perceptions of end-of-life care in an urban ICU. Dynamics 16(3), 22-25.

Lam P, Beaulieu M (2004). Experiences of families in the neurological ICU: a "bedside phenomenon". Journal of Neuroscience Nursing 36(3), 142-146, 151-155.

Lee LY, Lau YL (2003). Immediate needs of adult family members of adult intensive care patients in Hong Kong. Journal of Clinical Nursing 12(1), 490-500.

Leung KK, Chien WT, Mackenzie AE (2000). Needs of Chinese families of critically ill patients. Western Journal of Nursing Research 22(7), 826-840.

Livesay S, Gilliam A, Mokracek M (2005). Nurses' perceptions of open visiting hours neuroscience intensive care unit. Journal Nursing Care Quarterly 14(1), 621-631.

Lorin S, Rho L, Wisnivesky JP, Nierman DM (2006). Improving medical student intensive care unit communication skills: a novel educational initiative using standardized family members. Critical Care Medicine 34(9), 2386-2391.
O'Malley P, Favaloro R, Anderson B, Anderson ML, Siewe S, Benson LM, Deane D, Feeney J, Keefer N, Mains J, Riddle K (1991). Critical care nurses' perceptions of family needs. Heart and Lung 20(2), 189-201.

Marco L, Bermejillo I, Garayalde N, Sarrate I, Margall M, Asiain MC (2006). Intensive care nurses' beliefs and attitudes towards the effect of open visiting on patients, family and nurses. Nursing in Critical Care 11(1), 33-41.

Mendonca D, Warren NA (1998). Perceived and unmet needs of critical care family members. Critical Care Nursing Quarterly 21(1), 58-91.

Mitchell ML, Courtney M (2005). An intervention study to improve the transfer of ICU patients to the ward - evaluation by family members. Australian Critical Care 18(2), 61-69.

Murphy PA, Forrester DA, Price DM, Monaghan JF (1992). Empathy of intensive care nurses and critical care family needs assessment. Heart and Lung 21(1), 25-30.

Neabel B, Fothergill-Bourbonnais F, Dunning J (2000). Family assessment tools: a review of the literature from 1978-1997. Heart and Lung 29(3), 196- 209.

Pochard F, Azoulay E, Chevret S, Lemaire F, Hubert P, Canoui P, Grassin M, Zittoun R, le Gall JR, Dhainaut JF, Schlemmer B; French FAMIREA Group (2001). Symptoms of anxiety and depression in family members of intensive care unit patients: ethical hypothesis regarding decision-making capacity. Critical Care Medicine 29(10), 1893-1897.

Soderstrom IM, Saveman BI, Benzein E (2006). Interactions between family members and staff in intensive care units -- an observation and interview study. International Journal of Nursing Studies 43(6), 707-716.

Takman C, Severinsoon E (2005). Comparing Norwegian nurses' and physicians' perceptions of the needs of significant others in intensive care units. Journal Clinical Nursing 14(1), 621-631.

Ucar FB, Selimen D (2005). The anxiety level of the patients' family having medical treatment and mechanical ventilation support by the intensive care unit. Connect: The World of Critical Care Nursing 4(3), 108-109.

Van Horn E, Tesh A (2000). The effect of critical care hospitalization on family members: Stress and responses. Dimensions in Critical Care Nursing 19(4), 40-49.

Verhaeghe S, Defloor T, Van Zuuren F, Duijnstee M, Grypdonck $M$ (2005). The needs and experiences of family members of adult patients in an intensive care unit: a review of the literature. Journal of Clinical Nursing 14(4), 501-509. 